\title{
Units of Production and Consumption: Reframing Social Housing as Sustainable Infrastructure
}

\author{
Steven A. Moore
}

Published online: 9 July 2014

(C) Springer International Publishing AG 2014

\begin{abstract}
Social housing in the United States is generally viewed as an unfortunate, yet necessary public entitlement required to keep poor citizens from becoming burdens in other ways to the more affluent citizens who pay taxes. This view derives from the utilitarian philosophical assumptions that are the basis of the US Constitution itself. This article reframes public understanding of social housing, without leaving our utilitarian framework, as an essential part of sustainable urban infrastructure. This transformation requires a three-step process that is ecological, social, and technical in scope, or ecosociotechnical. Step one is to revisit our utilitarian assumptions in order to reconsider the meaning of the "greatest-good" principle. Reconsidering dominant socioeconomic assumptions that guide the generally unsuccessful approach to social housing in the United States, of which building energy systems are a part, requires a revised problem statement. Step two requires reframing the concept of infrastructure to be the endproduct of our building culture rather than the enabling means of urban life. Finally, step three requires reframing social housing so that it is better understood, and therefore designed to be reciprocal units of production rather than only units of consumption-units of providing rather than only units of receiving. In this final section, an on-going case study demonstrates how net-zero energy social housing might provide the ecosociotechnical goods required to sustain cities. The consequences of this analysis for energy studies are significant because they require energy system designers, policy-makers, and managers to consider the social as well as the purely technical dimensions of energy flows.
\end{abstract}

\footnotetext{
S. A. Moore $(\bowtie)$

The University of Texas at Austin, 310 Inner Campus Drive, Austin, TX 78712, USA

e-mail: samoore@austin.utexas.edu
}

Keywords Ecosociotechnical · Distributed infrastructure Social equity $\cdot$ Social housing

\section{Introduction}

It is now commonly recognized that the production, operation, and decommissioning of architecture, conceived broadly as the built environment, are the single greatest contributors to climate change [1]. Among types of architecture, housing consumes the greatest amount of energy and is, therefore, a major focus of research $[2,3]$. And among types of housing, at least in the United States, social housing is thought to be the most problematic to manage because it introduces so many politically controversial and extra-scientific factors. Yet, rather than reject social housing as a topic for building energy research, this analysis finds in such confounding factors precisely the conditions required to reconsider building energy research from a new perspective. Simply put, including extra-scientific factors in building energy research require reexamination of the scope and nature of the ecosystem(s) being studied. In this analysis, the ecosystem of social housing is understood to include not only (1) building forms, materials, sites, equipment, energy and the consequences of their production, as well as (2) the human beings who inhabit, design, and operate it, but also (3) the "institutional regimes" [4•] that benefit from what social housing provides. ${ }^{1}$ In this broad context, social housing is used as but one example of an architectural type that challenges dominant economic and scientific assumptions concerning conventional responses to climate change and the broader problem of sustainable urban development.

\footnotetext{
${ }^{1}$ By "institutional regime", Nicol refers to "the more or less coordinated set of public policies, property rights and contracts that relate to all users of a resource, who in turn affect the reproductive capacity of the resource and hence its sustainability" (p.4).
} 
Others have argued that contemporary building energy research reveals two related patterns: First, unlike the basic researchers of prior decades, contemporary building energy researchers are theoretically committed to interdisciplinary, context-dependent or applied research $[5,6,7,8]$. But second, there are limits to the kind and number of extra-scientific factors that building energy researchers can, or are willing to consider in the pursuit of more efficient systems [9•]. These two key words - efficient and system - which typically serve as the objective of building energy research, require definition before this analysis can move on to a three-step logic that will propose a new approach to building energy research.

\section{Efficiency}

In philosophical terms, the concept of efficiency is an abstract ratio of output to input. Put in the dominant economic context of our time, that of neoclassical economics, we tend to favor ratios that yield higher outputs with minimal inputs. Philosophers, however, caution their readers that, in the end, the mathematics of efficiency have no independent moral ground. This is to say that we might calculate the efficiency of a life-saving drug on the one hand, and of a mass murderer on the other, using the same formula. A higher ratio in both calculations is not necessarily a good thing. The question remains: efficient toward what end? Or, put in the most simple of terms, the efficiency of one part of any system should not be confused with the efficacy of the system as a whole. In the case of sustainable building energy research, the end assumed is the reduction or mitigation of climate change, which is surely an ethically noble cause - but, one made far more complex by considering the social or extra-scientific content of the system in question.

\section{Systems of Receiving and Providing}

The philosophical question becomes more complex when we consider the efficacy of the system, or the set of interacting components that comprise a whole. How should researchers understand a system of social housing? As a sub-system of the city? As a sub-sub-system of an ecosystem? If researchers accept as unproblematic the premise that all systems are cosmologically nested, then s/he can consider social housing as a coherent system in itself, but one which also has external consequences within higher-order ecosystems such as the city.

If researchers also accept the premise that all systems are dynamic, rather than static, it becomes necessary to account for how any particular system both receives and provides value over time [4•]. Although it may be counter-intuitive, at least within the dominant economic framework of our time, it is necessary to assess not only how social housing receives value from society in the form of economic subsidies, but also how it provides, or might provide, value in the form of ecosystem services (conceived broadly). The Millennium Ecosystem Assessment of 2005 [10] characterized the services that humans receive from "nature" as four-fold: provisioning, as in the providing of food; regulating, as in the controlling of climate; support, as in plant or crop pollination; and cultural services, as in recreation or spiritual inspiration. If the analogy of ecosystem services is extended to the built environment, when it is considered part of nature, then social housing can provide shelter and energy; regulate the microclimate; and support the cleansing of water and wastes, as well as contribute to the cultural sense of place and its beauty. The point is that to study only the reduction of consumption is to study only half of the system $[5,6,7,8,9 \cdot]$.

Similar arguments have been made in the related fields of landscape architecture [11, 12] and urban studies [13]. For example, one cannot study how the relatively rich buyers of inner-city homes consume latent value without also studying the production of expendable capital. Put a bit differently, the design of any system, including an energy system, is not an abstract or context-independent exercise because consumption is a function not only of environmental context (i.e., how hot or cold it is), but also of social context (i.e., peoples' practices and habits). From an efficacious as well as an ethical perspective, the design of an "efficient" or sustainable energy system must be, then, context-dependent-which is to include extra-scientific variables $\left[14 \bullet, 15,16,17 \bullet \bullet .^{2}\right.$

Such logic does, however, contradict the popular understanding of efficiency as being related to mass production, low cost, and universality. The contradiction exists because energy system designers tend to view human behavior as the confounding variable in otherwise beautifully predictable systems comprised of pipes, wires, circuits, and flows. This is hardly a surprising observation because system designers are typically trained to predict and control things, not people. To be clear, the suggestion in this line of reasoning is not that we should train designers to predict and control human beings as well as things. This has been the fear of anti-moderns since the birth of the Enlightenment, such that most designers have avoided "human engineering" like the plague. Rather, the suggestion is that to design efficient whole systems of receiving and providing, or producing and consuming, messy human factors must be considered. But, how?

The deceptively simple suggestion made here is that someone needs to ask fellow citizens how they want to live, and in the process, study how they actually $d o$ live. It is neither

\footnotetext{
${ }^{2}$ There is a substantial literature, briefly referenced here, that seeks to understand the so-called "rebound effect," or, the phenomena of increasing consumption by users based on their perception of prior decrease in system consumption, or an increase in system efficiency. The rebound effect is but one dimension of the extra-scientific variables found in urban systems. For example, Sovacool (2014) recently conducted an exhaustive content analysis of 4,444 energy research articles and concluded that there are 75 distinct energy research topics that would benefit significantly by mixed research methods that include the social sciences.
} 
efficient nor prudent for designers to assume (a) they know best, or (b) simply ignore the social side of the system because it is too complex or unruly. Expanding the problem definition in this way will require not only different training for system designers, but transdisciplinary [18•] teams that include not only designers and social scientists, but also users themselves.

Having now defined critical terms that normally remain in the background, the sections that follow develop a three-step logic that redefines the problem of housing the poor as but one layer of the onion. Step one reframes the socioeconomic assumptions that guide the generally unsuccessful approach to social housing in the United States, of which building energy systems are a part. Step two reconsiders the historical definition of infrastructure as the public means that enable private ends. And, step three introduces a case that employs a new approach to energy research for social housing. The tentative claim made is that such an integrated approach to social housing may also provide some of the ecosociotechnical "goods" required to sustain cities as functional ecosystems.

\section{Step One: The Utilitarian Calculus of Social Goods}

Social housing can be defined as the construction of homes, economically subsidized by society, to prevent poor families from becoming burdens to society by succumbing to conditions of sickness, unemployment, or social disruption that are linked to homelessness and environmental degradation. This concept is, at its core, an economic and legal one that derives from the utilitarian calculus initially developed by the British philosopher Jeremy Bentham (1748-1832). What Bentham recognized was that the poverty, sickness, and the general malaise of the poor was not, as people tended to believe at the time, punishment by a higher authority for immoral or slothful behavior. Rather, more often than not, chronic poverty is the consequence of growing up in environmentally degraded conditions with inequitable access to education and health care. Although considered very radical at the time, scholars generally agree that Bentham and his followers contributed to the epistemological assumptions embodied in the US Constitution and their subsequent codification in the laws of the States. Reconsidering current building energy policy might appropriately begin, then, by briefly reconstructing utilitarian assumptions because engineering decisions tend to follow economic theories of efficiency and value generally accepted by society.

The primary axiom of utilitarianism is the "Greatest Happiness Principle", which holds that "it is the greatest happiness of the greatest number that is the measure of right and wrong" [19]. From this axiom, subsequent law-makers have constructed codes designed to ensure the minimum welfare of all citizens. Their reasoning is that that the wellbeing of the social-economy as a whole requires the full employment and productivity of the citizenry. In turn, full employment requires society to minimize the negative economic flows that result from the disability of workers. Utilitarian logic has, of course, been contested and interpreted in a variety of ways, particularly with regard to the role of government in achieving the greatest amount of social goods. Although the history is long and complex, a brief review of two opposing interpretations of utilitarian logic will characterize the field: the dominant neoclassical view, and the emergent empirical view of the greatest good.

The Dominant Neoclassical View of the Greatest Happiness Principle

Proponents of neoclassical capitalism, the dominant economic logic that developed in Bentham's time, generally endorse the idea that there is a necessary trade-off between "equity and efficiency, between fairness and economic growth" [20••]. Neoclassical economist and Nobel Laureate Milton Friedman (1912-2006), for example, reasoned that it is natural and necessary for some people - characterized by Friedman as "patrons" [21•-168] — to accumulate significant wealth in order to invest in industries requiring large amounts of capital that will, in turn, stimulate general economic growth to the benefit of all. In a utilitarian frame, neoclassical economists hold that the well-being of the greatest number of people actually benefits from unequal wealth distribution by "allowing for the intrinsic heterogeneity of populations" [21•-169]. ${ }^{3}$

Implicit in Friedman's notion of social heterogeneity is a seemingly natural hierarchy of "intrinsic" human capabilities in which some of us are simply more capable, driven, or intelligent than others. It is, then, through the "cooperation and coordination," or reciprocity, of such higher functioning men that wealth is created without "coercion" by the state [21•-168]. In his subsequent analysis of "miscellaneous welfare measures" Friedman specifically decries "public housing" because, "It can be justified, if at all, only on grounds of paternalism that the families being helped 'need' housing more than they 'need' other things but would themselves

\footnotetext{
${ }^{3}$ In Capitalism and Freedom, Friedman argues that, "The heart of the liberal philosophy is a belief in the dignity of the individual, in his freedom to make the most of his capacities and opportunities according to his own rights, subject only to the proviso that he not interfere with the freedom of other individuals to do the same. This implies a belief in the equality of men in one sense; in their inequality in another. Each man has an equal right to freedom. This is an important and fundamental right precisely because men are different, because one man will want to do different things with his freedom than another, and in the process can contribute more than another to the general culture of the society in which many men live." [21•-195]
} 
either not agree or would spend the money unwisely" [21 •178].

There is a very curious and circular pattern in Friedman's reasoning with regard to "public" or social housing. On the one hand, he argues for the individual right of every person, including the poor, to make their own choices, no matter how illinformed or unwise they may be. But, on the other, he never considers the possibility that the poor might themselves make good partners in reciprocal efforts of "cooperation and coordination" to create wealth, reduce sickness, or make the city sustainable. The underlying assumption is, apparently, that the poor themselves have nothing to contribute to understanding the conditions in which they themselves live, and so, it would be unwise or inefficient to include them in decision-making. Rather than debate Friedman's argumentative claim at this juncture, it is more efficient to note that his logic relies on the assumption that there is but one kind of intelligence and one kind of knowledge possessed by patrons and other "reasonable men." This is a claim that is now very hard to support [22••, 23]. In this context, the proposal made herein is not to paternalistically experiment on the poor, but to experiment with them.

\section{The Emergent Empirical View of the Greatest Good}

More recently, economists have found empirical evidence that contradicts the dominant neoclassical interpretation of the Greatest Happiness Principle. In their exhaustive review of contemporary economic literature, Benner and Pastor have found that the necessary accumulation of wealth by the few is more an ideological position than an empirical one. Rather, they have empirically demonstrated that "social equity is correlated with economic growth and the stronger studies [included in their review] have provided evidence of not just correlation, but probable causation, with improving social equity actually contributing to more rapid economic growth" [20•-1]. This finding turns the dominant interpretation of the Greatest Happiness Principle on its head. Rather than justifying the unequal distribution of wealth on the grounds of "trickle-down economics,"4 advocates of "inclusive innovation" [24] find that increasing social equity is not only fairer, but it also promotes regional economic growth.

To be clear, the causal factor in Benner and Pastor's findings is not simply that people who receive equitable treatment are happier, and therefore more productive. In addition, their findings are two-fold: First, that people with different kinds of experience have context-dependent knowledge that is necessary to problem-solving in unique conditions [see also 25•]. And second, that given the opportunity, poor people can positively contribute to economic growth in unexpected ways because of their "situated knowledge" [22••]. In Benner and Pastor's own

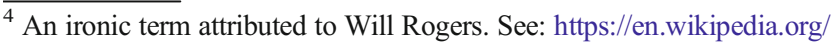
wiki/Trickle-down economics.
}

words, "Our hypothesis is that these diverse knowledge communities facilitate a region's ability to both better identify growth opportunities and to respond collectively to those opportunities quicker and with less social and political conflict-in short, that knowing together contributes to growing together" [20••; see also 25•]. As did Bentham, new economic theorists see the poor as untapped collaborators with different and relevant kinds of problem-solving knowledge, rather than as anonymous and unproductive consumers of scarce resources.

In the context of social housing, these findings require at least three alterations to the neoclassical model: First, society would be prudent to recognize the residents of social housing, not as negative drags to the economy, but as underutilized human resources to improve it. Through the co-construction of diverse regional knowledge communities new kinds of systems might be developed. Second, the residents of social housing are the necessary social dimension of the energy ecosystem being designed. Without including them in the design and operation of a coherent energy system, we will be designing only half of the system - an "efficient" system of production likely to fail.

And third, the neoclassical model considers only the resources received by social housing and ignores those provided by it. In the most limited measurement, shelters are provided. And when limited to this dimension, it is logical to minimize economic input into the system by building as inexpensively as possible. However, a somewhat broader view, favored by most building system researchers, is to invest in energy efficient systems that will (a) reduce monthly energy costs to residents, and perhaps more significantly, (b) reduce overall contributions of the sub-system to climate change. But, even this broader view of the system fails to consider what other economic, environmental, and social goods might be created by reimagining the boundaries of social housing. Rather than only a place to warehouse people perceived as unproductive, an expanded system might also provide storm-water sequestration and treatment for the adjacent neighborhood, public space, cooperative neighborhood childcare, carbon sequestration functions, or distributed energy production for the city as a whole. In purely economic terms, a recent study in Austin, TX, documented that a \$56 million 2006 municipal bond issue, raised exclusively to fund social housing in the city, catalyzed $\$ 865$ million in regional economic activity [26]. This is evidence that that the "institutional regimes" related to social housing produce benefits at the regional level as well as receive them $[4,20 \bullet \cdot$. These are but a few of the reciprocal urban ecosystem services that might be provided by reframing the very idea of social housing as one unit of a larger urban ecosystem in which the "urban metabolism" is inverted [12] to become ecologically productive as well as consumptive. As argued above, building energy research must consider both sides of the system to be efficacious.

At this point in the analysis it is important to recognize that moving from a neoclassical economic model to a new 
economy model does not require that we also leave the utilitarian framework that is the foundation of our society. For the moment it means only that we take advantage of more recent empirical data and question some of the ideological assumptions of the past. If the reasoning in this first-step holds up to scrutiny, the next step will be to redefine social housing, not as a paternal subsidy to the unwilling poor, or as giving away some portion of a fixed amount of scarce resources, as is envisioned by neoclassical economists, but as a necessary dimension of sustainable public infrastructure.

\section{Step Two: Reframing Infrastructure as Ends and Means}

This step requires, first, that the concept of infrastructure be reexamined through critical lenses that reflect dynamic conditions. Second, it is necessary to consider how changing conditions might contribute to altering our frame of interpreting social housing. And third, this step concludes by arguing that it is necessary to redefine the problem at hand. The design problem faced by energy system researchers is not development of more efficient building units, but the transformation of building culture as a whole.

\section{Infrastructure as Means in Neoclassical Economics}

In developed economies, infrastructure has proliferated to include such artifacts as transmission towers, landfills, bike lanes, and dikes. The basic concept has, however, not changed very much since its initial appearance - moderns still understand infrastructure to be the public technological means that enable the private ends we desire. The term is a relatively young one and was initially coined by the French c.1875. In French, the term was initially limited to the military context of supplying materiel to the war front, but by the early decades of the twentieth century, the term was adopted in English and also referred to "the roads, bridges, rail lines, and similar public works that are required for an industrial economy, or a portion of it, to function" [28], emphasis added]. By midcentury, the term was expanded to include "basic social services such as schools and hospitals" [28]. As the service economy has increasingly overtaken the industrial economy, the term has expanded once again to include organizational capacity such as corporate branch offices, the franchises of fast food restaurants, or the information "cloud." So, when we refer to infrastructure in the present, we still refer to what is required for "an industrial economy, or a portion of it, to function." The neoclassical economic assumption implicit in this characterization of a robust "industrial economy" is that life-diminishing means, like coal-fired electrical generators or ten-lane freeways, only enable the distant ends we imagine to be the good urban life. Just as inequitable distribution of wealth is justified by neoclassical economists on the grounds of more efficient ends, so too are life-diminishing means.

It would be wrong, however, to characterize all modern infrastructure as single-purpose, life-diminishing means. The Brooklyn and Golden Gate Bridges are, for example, considered beautiful contributions to urban life in those cities. But more to the point is Boston's Fenway, designed by Frederick Law Olmsted. The "Fens" is, at once, a constructed wetland that treats storm-water, a carbon sequestration system, habitat for multiple non-human species, a sewer, a streetcar line, and a beloved public park. In all, it manages flows of humans, nonhumans, and water of different categories. It is what might be called a complex or multi-purpose infrastructure. Or, as Star has put it, "Infrastructure is both relational and ecological- it means different things to different groups, and it is part of the balance of action, tools, and the built environment, inseparable from them" [29*0-377]. Following Star and the example of Boston's Fenway, social housing might, then, be reframed by the diverse knowledge communities defined above as complex, multi-purpose infrastructure. The question is, how?

\section{Frame Analysis and Technological Change}

The professional discussion concerning the development of distributed infrastructure is a second model from which to learn. Turkson [30], Takahashi \& Baker [31], Del Monaco [32], Feinstein [33], and many others have conducted research that supports movement away from centralized infrastructural systems to those that are distributed. The distinction is that centralized systems were conceived in an era of cheap energy, isolated capital, and based on the assumptions of economies of scale, which is to say that, from a management perspective it's more efficient to build one big energy plant than ten little ones. However, as energy has become more expensive, capital less isolated, and the efficiency embedded in economies of scale has been eroded by massive line-losses in the system, centralization no longer makes economic or environmental sense. The good news is that as researchers are reconsidering the economic and environmental consequences of maintaining the status quo, they are also confronting the social dimensions of infrastructural systems.

Philosopher Langdon Winner has long held that different kinds of technological systems have different kinds of politics [34••]. For example, the extreme danger inherent in operating nuclear systems or deep-water, off-shore oil rigs requires social relationships within the system that are equally hierarchical, rigid, and undemocratic. In contrast, the low level of danger inherent in operating small-scale solar or wind systems allows for, but does not cause, social relationships within the system that are non-hierarchical, loose, and more democratic. Although the popular literature about solar energy, in particular, is littered with off-the-grid, anarchist delusions, Winner's analysis still holds. The move toward more efficient, smaller 
units of energy production will require new social arrangements to manage them, and perhaps even own them! The point is that the social structures of any utility must be ordered in a manner that not only serves investor interests, and the interests of citizen-consumers, but that also reflect and reinforce the capacity of the poles, switches, and lines - or alternately, panels and bio-swales - that are managed. Different technologies require, and reflect, different social systems of management and community engagement.

This logic suggests that infrastructural systems will have social consequences whether we consciously design them or not. We are, then, ethically, and practically bound to consider the social dimension, as well as the technological and ecological dimensions of change as a matter of design.

The significance of this public conversation concerning distributed energy production is that public and professional understanding of infrastructure is being "reframed," and in a more substantive way than simply expanding the kinds of artifacts in the landscape included under that umbrella term. Being "reframed"- a term initially coined by psychologist Erving Goffman [35••] and expanded by Wiebe Bijker [36•] - suggests that different "relevant social groups" [37•] perceive and interpret technologies in different ways. Another way to say this is that social groups, like engineers, lawyers or architects, are themselves constituted by common interpretive frames developed through years of education, work, and play. The implication of Goffman's insights are that if infrastructures are interpreted, or framed, as simple, single-purpose systems by one social group, they can also be re-framed as complex, multipurpose systems by other groups, including the diverse regional knowledge groups discussed above. The process of reframing is, of course, a slow, highly social and political one.

There is, then, a benefit to considering the problem of climate change through new lenses. That is the opportunity to reframe the very idea of infrastructure itself as a concept relevant to current conditions. Reframing the meaning of infrastructure might condense, if not overcome the modern opposition between undesirable, yet enabling technological means and the ends to which society aspires - the greatest happiness for the greatest number. The project of reframing the concept of centralized infrastructure to distributed, or from simple and single-purpose to complex and multi-purpose, will require nothing less than the transformation of our building culture - a project that is always underway.

\section{Redefining the Problem}

Howard Davis has defined the concept of building culture as, "the coordinated system of knowledge, rules, procedures, and habits that surround the building process in any given place and time" [38-5]. Our built environment is, in Davis' view, largely a product of seemingly informal cultural practices and the formal codes that order them. Our codes are sometimes tacit, but increasingly, and explicitly, controlled by private sector standard-making organizations such as ASHREA (formerly the American Society of Heating, Refrigerating and Air Conditioning Engineers) or ANSI (The American National Standards Institute) [39•]. Although the codes, standards, and regulations legislated by these groups are intended to be national, or even international in scope, in the United States it is municipal governments that retain final authority to adopt and/or modify them. This unique legal structure opens the door to experimentation at the local level by the diverse knowledge groups discussed above [40॰]. The problem-athand is, then, not the design of singular mechanical appliances that are ever-more efficient and context-independent, but the reconstruction of context-dependent building culture itself.

Such a project will require building researchers to act, not only on a project-by-project basis, but also in the professional and academic organizations that establish national, state, and local standards and codes. This recommendation for political activity by researchers sets up the final step in this analysis, which is a brief case study that anticipates an approach to social housing as complex, multi-purpose infrastructure. It is a case in which inhabited infrastructure aspires to be both means of and ends to a sustainable city.

\section{Step Three: Social Housing as Units of Production and Consumption}

The Green Alley Demonstration Project (GADP) of Austin, Texas is an on-going collaboration between the University of Texas Center for Sustainable Development (UTCSD), the Guadalupe Neighborhood Development Corporation (GNDC), the Austin Community Design and Development Center (ACDDC), and the City of Austin (CoA). ${ }^{5}$ Together, the team is engaged in collaborative experimentation, or "inclusive innovation," to redevelop an environmentally degraded alley in east Austin that is the home of a stable and predominantly lower-income Latino neighborhood threatened by the economic forces of gentrification (Fig. 1). The team is, then, not only a "diverse knowledge group," as proposed above by Benner and Pastor, but also an action group, or what could be called a diverse "think \& do tank." The long-term goal of this think-\&-do tank is to demonstrate how the insertion of alley-flats, or subsidized energy-efficiency homes of 800 square feet or less, can not only resist the economic forces of gentrification, and thus contribute to the stabilization of a threatened community, but also produce energy, sequester

\footnotetext{
${ }^{5}$ This project was the recipient of the 2014 "Place Research Award" by the Environmental Design and Research Association (EDRA).

${ }^{6}$ This term was developed by the Center for Global Development. See: http://www.cgdev.org/publication/building-think-and-do-tank-dozenlessons-first-dozen-years-center-global-development.
} 
Fig. 1 Ribbon cutting ceremony for Alley Flat \#2. This unit provides fully accessible, low cost, and low-energy housing for the great-grandmother pictured center, and her immediate family who live in the "big house"



storm-water, and filter that water before returning it to the aquifer below. In this case, social housing has been reframed to be reciprocal units of production and consumption-a combination that benefits not only residents, but also the city as a whole. To do so, traditional concepts of private and public property must be reconsidered as reciprocal actors in a municipal ecosystem.

\section{Distributed Housing Infrastructure}

Just as centralized energy infrastructure, as discussed above, has become an outmoded concept, a similar claim can be made about centralized housing infrastructure. The contemporary literature regarding social housing [41] has demonstrated that some populations benefit from "supportive housing" that requires just enough centralization to afford specialized living and learning facilities. Other populations, however, benefit from distribution into economically diverse neighborhoods. Integration provides, but does not coerce, diverse social groups with an opportunity for "social learning" [42]. This basic strategy was implemented in Austin by GNDC, a local affordable housing provider, as early as the 1980s.

Although affordable housing providers, energy system analysts, and municipal infrastructure managers rarely talk to each other, faculty and students from the UT CSD were able to recognize the opportunity to marry these three systems into a single, hybrid, ecosociotechnical system located in Austin's alleys. To do so, it was necessary to get residents, engineers, and architects from multiple city departments, a landscape architect, a public information specialist, and housing advocates to talk with each other early in the programming and design phase. This transdisciplinary conversation is far from complete, but remains promising.

\section{Context-Dependent Whole-System Design}

A second opportunity was recognized by UT students and faculty in conducting GIS analysis of land-use patterns in the threatened neighborhoods. Simply put, over $60 \%$ of neighborhood properties were, in 2007, owned outright by long-term residents, but the lots, by urban standards, were under-developed. In other words, many families were housepoor, with non-liquid capital that could be prudently made available only for redevelopment of the subject property. The insertion of very small houses in the back yards of families unable to pay their taxes became the collective project of the think-\&-do tank. These small houses, or alley flats, could provide either new rental income, or new spaces for extended families to consolidate economic liabilities, and thus avoid tax foreclosure.

GIS analysis also demonstrated that on the basis of current zoning regulations in the GNDC operating area, up to 3,300 units could be constructed by right. But if ordinances could be changed even slightly, as is being considered in the Land Development Code currently being re-written in accordance the 2012 city plan, Imagine Austin, up to 44,000 units could be realized. Even if only 7,000 units were constructed, each having a $2.4 \mathrm{KW}$ solar array and a 200 gallon cistern, 16,800 fewer tons of carbon dioxide would be emitted annually; the equivalent of 3,426 cars would be taken off local roads, the equivalent of 25,350 trees would be planted, and 
7,000 small families or seniors would have utility bills of less than $\$ 25$ per month to pay [43]. In other words, the urban metabolism could be shifted measurably from one of consumption to one also of reciprocal production (Fig. 2).

Although these quantities are modest, given the scale of the problem, the GADP is not intended to single-handedly satisfy the goals of the City's 2020 Climate Protection Plan [44]. Rather, the project is intended to demonstrate, through trial and error over many years, how the technical and social dimensions of several kinds of infrastructure - energy, transportation, solid waste, storm-water, and social housing - can be sustainably co-constructed by those, including the poor, who are directly affected. Although what has been constructed to date has been more modest than the multi-purpose complex infrastructure imagined by students, perhaps the greatest success has been the social capital built between the city, the community, and the university. That transdisciplinary trust opens the door to continued incremental and reciprocal experimentation.

\section{Net-Zero Energy Social Housing}

The concept of distributed energy production makes sense under current conditions - fuel is just too expensive to lose
$65 \%$ of its capacity through line-losses inherent in centralized systems. The concept is, however, still reductive because it attempts to solve only the production, or technical-side of the problem. It is disengaged from the consumption, or social-side of the problem. This is why system designers of distributed energy production prefer to install solar arrays on the rooftops of parking garages or large industrial structures - they can be managed using the same corporate social or business models developed in the management of centralized natural gas or coal burning plants. It is far more efficient to negotiate terms with a single owner, especially one with sophisticated staff, rather than with thousands of home owners who are suspicious of government, don't hold regular office hours, and who would prefer to speak Spanish. Atomizing energy production systems to the much smaller roofs of distributed social housing requires another kind of social organization within the utility itself. It also requires the design and implementation of new social and economic relationships with citizenconsumers.

A key finding of this analysis is, then, that the design of such extra-scientific systems is the missing link, or "reverse salient" required to realize net-zero energy social housing as a model of sustainable infrastructure. The term "reverse salient"
Fig. 2 GIS analysis of Austin's alley network and "overlay" zoning ordinance that allows the construction of Secondary Dwelling Units, or alley flats

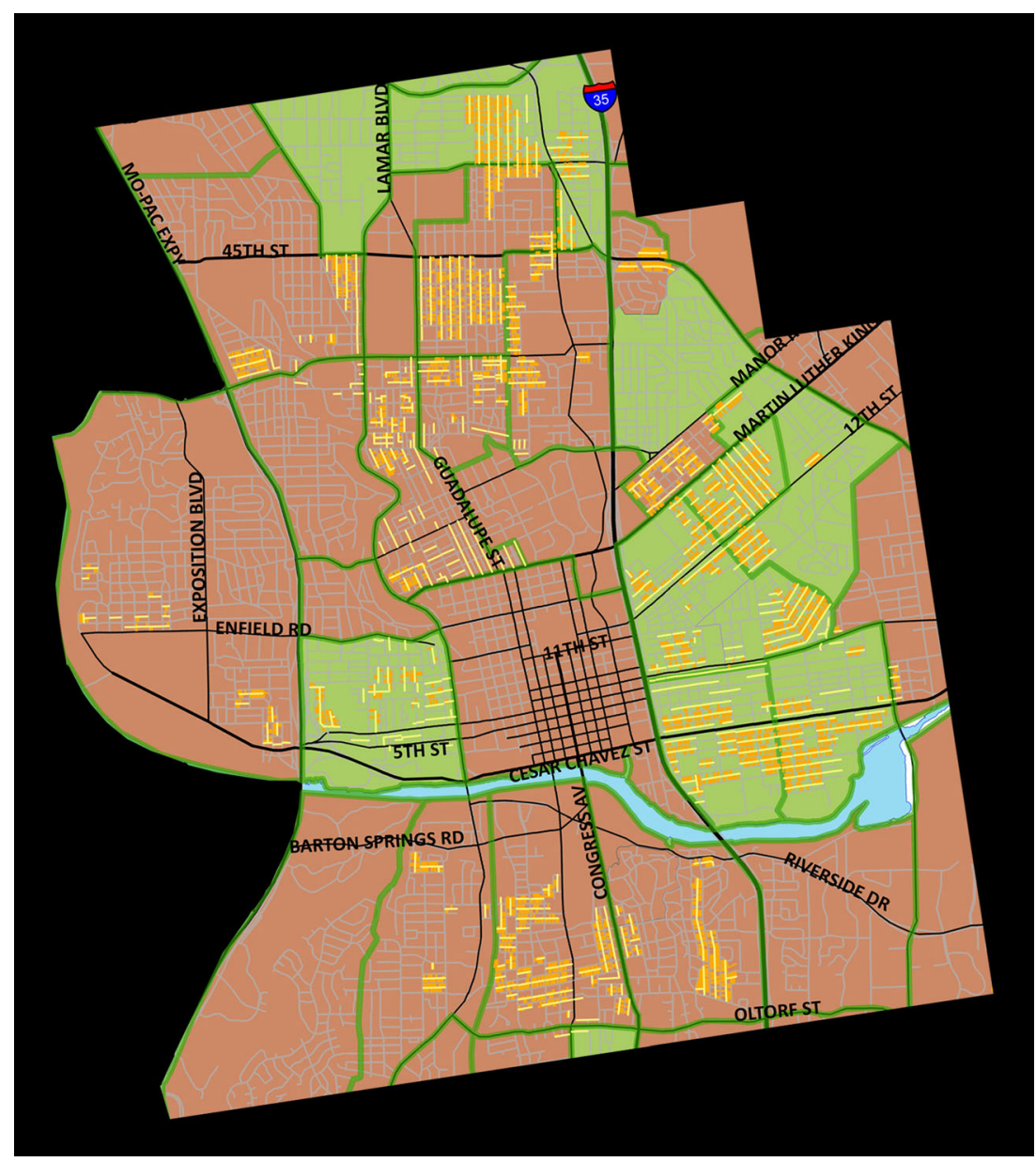


is another military one appropriated by science and technology studies scholar Thomas Hughes [45], in his analysis of technological systems. The term refers to a component of the system being studied that, because of its insufficient development, prevents the technological system as a whole from achieving the stated goal. The social organization of modern systems of distributed infrastructure is, then, the reverse salient of sustainable urbanism.

\section{Conclusion}

The emergence of the green building movement in the United States demonstrates acceptance by most citizens that the production, operation, and decommissioning of architecture is the sector of the economy that contributes most to climate change. Within the built environment, housing is recognized as the building type that provides the greatest opportunity for more efficient energy production, conservation, and management. Social housing is, however, generally excluded from energyrelated investment in the United States because the dominant neoclassical economic view is that the construction of social housing of any kind is a bad investment, destined to failure, because it is both paternalistic and inefficient. This analysis has, however, demonstrated that within the extra-scientific conditions of social housing lies the suppressed variables, or reverse salient, required to make the whole system viable.

A third finding of this analysis is that the neoclassical view of social housing is an ideological one designed to justify inequitable social conditions that themselves suppress attainment of the greatest amount of happiness for the greatest number of people. Rather than envisioning a building culture as being only the rules to afford efficient production and maximum profit, the analysis demonstrates that truly efficient whole systems must be designed with production and consumption, receiving and providing, technology and society, means and ends in mind. Achieving this goal will require new kinds of social behavior, not only among the poor, but also among the professional community that designs infrastructure as well as the corporate and municipal structures that manage and own infrastructure.

And finally, the very concept of infrastructure as the means that enable an industrial economy to operate must be reimagined. In its place, diverse think-\&-do groups, like the one forged through the Green Alley Demonstration Project, must co-construct sustainable, inhabited infrastructures through transdisciplinary experimentation, collaboration, and cooperation at the local level. Social housing, rather than being a poor investment, or a poor opportunity for building energy research, is probably the best way to realize a sustainable infrastructural system composed of distributed and reciprocal units of production and consumption.
Acknowledgements I would like to thank Jane Winslow and the referee(s) who so generously helped to improve this text through their comments and criticisms.

\section{Compliance with Ethics Guidelines}

Conflict of Interest Steven A. Moore declares that he has no conflict of interest.

Human and Animal Rights and Informed Consent This article does not contain any studies with human or animal subjects performed by any of the authors.

\section{References}

Papers of particular interest, published recently, have been highlighted as:

- Of importance

-. Of major importance

1. Hajer M. The politics of environmental discourse: ecological modernization and the policy process. Oxford: Oxford University Press; 1995.

2. Mol AJP. Globalization and environmental reform: ecological modernization and the global economy. Cambridge: MIT Press; 2001.

3. Jensen JOKG-H. Ecological modernization of sustainable buildings: a Danish perspective. Build Res Inf. 2008;36(2):146-58.

4. Nicol LA, Knoepfel P. Resilient Housing: a new resource-oriented approach. Build Res Inf. 2014;42(1):1-11. From a European perspective the authors develop a socio-technical approach to housing.

5. Cole RJ, Oliver A, Robinson J. Regenerative design, socioecological systems and co-evolution. Build Res Inf. 2013;41(2): 237-47. The central concept-that social and ecological systems "co-evolve"-is also central to the position taken in this article.

6. Millennium Ecosystem Assessment (MA). Ecosystems and human well-being: synthesis. Washington, DC: Island Press; 2005.

7. Hamilton IG, Summerfield AJ, Steadman P, Oreszczyn T, Lowe R. Uptake of energy efficiency interventions in English dwellings. Build Res Inf. 2014;42(3):255-75.

8. Lees T, Sexton M. An evolutionary innovation perspective on the selection of low and zero-carbon technologies in new housing. Build Res Inf. 2014;42(3):276-87.

9. Devine-Wright PWW, Henshaw V, Guy S. Low carbon heating and older adults: comfort, cosiness and glow. Build Res Inf. 2014;42(3): 288-99. References 5, 6, 7, and 8 are part of a Special Issue in Building Research \& Information that investigates the social side of energy system performance. See also BRI Special Issue 43(4) on "Energy retrofits of owner-occupied homes." This journal is an outstanding source of ecosociotechnical research.

10. Gluch PMG, Thuvander L, Baumann H. Charting corporate greening: environmental management trends in Sweden. Build Res Inf. 2014;42(3):318-29.

11. Boeri S. Five ecological challenges for the Contemporary City. In: Doherty MMAG, editor. Ecological urbanism. Cambridge: Lars Mueller Publisher; 2010.

12. El Kafif M. Coding Urban Metabolism. In: Scenario Journal 02 (Spring). 2012. http://scenariojournal.com/article/coding-urbanmetabolism/. Accessed 22 Feb 2014.

13. Lees L, Slayter T, Wyly E, editors. The gentrification reader. Routledge: London; 2010. 
14. Deutsch M. Life cycle cost disclosure, consumer behavior, and business implications. J Ind Ecol. 2010;14(1):103-20. A significant contribution to the literature concerning the "rebound affect".

15. Kaenzig J, Wüstenhagen R. The effect of life cycle cost information on consumer investment decisions regarding eco-innovation. J Ind Ecol. 2010;14(1):121-36.

16. Schneider F, Kallis G, Martinez-Alier J. Crisis or opportunity? Economic degrowth for social equity and ecological sustainability. Introduction to this special issue. J Clean Prod. 2010;18(6):511-8.

17.• Sovacool, Benjamin K. "Where are we Going Here: Analyzing fifteen years of energy scholarship and proposing a social science research agenda." Energy Research \& Social Science 2014;1(29). This is a very significant new piece of research that appeared in this new journal devoted to the interdisciplinary study of energy issues.

18. Dooling S, Greve A. Urban ecology and ecological gentrification: complexity and consequences in human-dominated systems. In: Association of Collegiate Schools of Planning Annual Conference. Milwaukee, WI. 2011. In this paper the authors contribute a definition of "transdisciplinary knowledge" that is very helpful.

19. Bentham J. Legislator of the World: writings on codification, law, and education. New York: Clarendon Press; 1998.

20.• Benner C, Pastor M. Buddy, can you spare some time? Social inclusion and sustained prosperity in America's Metropolitan Regions. In: MacArthur Foundation Network on Building Resilient Regions. 2013. Using empirical data, this report turns on its head the dominant neo-classical economic assumptions concerning the necessity of capital accumulation in the hands of a few.

21. Friedman M. Capitalism and Freedom / Milton Freedman, with the assistance of Rose D. Friedman; with a new preface by the author. Chicago: University of Chicago Press; 1982. This is a primary text that embodies neo-classical economic assumptions.

22.• Haraway D. Situated knowledge: the science question in feminism and the privilege of partial perspective. In: Feenberg A, Hannay A, editors. Technology \& the politics of knowledge. Bloomington: Indiana University Press; 1995. p. 175-94. Haraway's critique of modern epistemology is a classic in the field.

23. Gardner H. The three faces of intelligence. In: Daedalus. Winter; 2002. 139-42.

24. Sociedad Latinoamericana de Estudios Sociales de la Ciencia (ESOCITE) and Society for Social Studies of Science (4S). 2014. Panel topic at: ECOCITIES, 20-23 August, at Buenos Aires.

25. Fischer F. Citizens, experts, and the environment: the politics of local knowledge. Durham; Duke University Press. 2000. Also; Fischer, Frank. 2009. Democracy \& Expertise: Reorienting Public Inquiry. New York: Oxford University Press. All of Fischer's work demonstrates how local knowledge is essential to achieve technological success.

26. Kretzmann JP, McKnight JL. Building communities from inside out: a path toward finding and mobilizing a community's assets. Skokie: ACTA Publications; 1993.

27. HousingWorks. 2012. The Economic Impact of General Obligation Bonds for Affordable Housing in Austin. Available at: http:// housingworksaustin.org/?post publications=the-economic-impactof-general-obligation-bonds-for-affordable-housing-in-austin. Accessed 27 June 2014.

28. Morris W, editor. American heritage dictionary of the English language. Boston: Houghton Mifflin Company; 1981.

29.• Star SL. The ethnography of infrastructure. Am Behav Sci. 1999;43:377. This is an early, and seminar analysis of infrastructure from the perspective of ethnography as well as science and technology studies (STS).

30. Turkson J, Wohlgemuth N. Power sector reform and distributed generation in sub-Saharan Africa. Energy Policy. 2001;29(2):13545.

31. Takahashi K, Baker S et al. 2005. Policy options to support distributed resources: a report to connective power delivery, Center for Energy and Environmental Policy.

32. Del Monaco J L, PE, P S E a G C (PSE\&G). The role of distributed generation in the critical electric power infrastructure. IEEE 2001 Winter Power Meeting. Columbus; 2001.

33. Feinstein CD, Orans R, et al. The distributed utility: a new electric utility planning and pricing paradigm. Annu Rev Energy Environ. 1997;22:155-85.

34.• Winner L. The whale and the reactor: a search for limits in an age of high technology. Chicago: University of Chicago Press; 1989. A classic in the field of science and technology studies that examines the human agency embedded in technological systems.

35.• Goffman E. Frame analysis: an essay on the organization of experience, with a New Foreword by Bennett Berger. Boston: Northeastern Press; 1974. Goffman demonstrates that different social groups perceive reality differently and thus expect social events and technologies to conform to their "frame of interpretation." This is a particularly important concept for building system researchers to appreciate.

36. Bijker WE, Bijsterveld $\mathrm{K}$. Women walking through plans: technology, democracy, and gender identity. Technol Cult. 2000;41(3): 485-515. Bijker expands Goffman's basic theory into the realm of technological change.

37. Cowan RS. The consumption junction: a proposal for research strategies in the sociology of technology. In: The social construction of technological systems. Cambridge: MIT Press; 1989. 260-2. Cowan defines the concept of "relevant social groups" responsible for technological change with precision.

38. Davis H. The culture of building. Oxford University Press: New York; 2006. A particularly brilliant analysis of the social content of technological systems as the built environment.

39. Busch L. Standards: recipes for reality. Cambridge: MIT Press; 2011. Busch demonstrates that the seemingly trivial, even boring, regulation of material standards has profound social consequence.

40. Moore SA, Wilson BB. Questioning architectural judgment: the problem with codes in the United States. London: Routledge; 2013. This recent book provides the background for this article.

41. Mueller E, Teague R. Affordable housing reader. Hoboken: Taylor and Francis; 2013.

42. Holden M. Social learning in planning: seattle's sustainable development codebooks. Prog Plan. 2008;69:1-40.

43. Moore SA, Palleroni S. Topics in sustainable development: the alley flat initiative, 2008 report. Austin: The University of Texas, Center for Sustainable Development; 2009. Available at: http://soa.utexas.edu/files/csd/CSD_AFI_2008.pdf. Accessed 5 Mar 2014.

44. City of Austin. (2007). Climate protection plan. Available at: http:// www.austintexas.gov/department/sustainability. Accessed 5 Mar 2014

45. Hughes TP. (1993 printing). Networks of power: electrification in Western Society, 1880-1930. Baltimore: Johns Hopkins University Press, Softshell Books ed; 1983. 